\title{
Determination of Sulfamethoxazole in Pure and Pharmaceutical Samples by Using Direct Method for Calibration Curve of Normal Spectrum of UV-Spectrophotometry
}

\author{
Sarra A. Abrahem* and Khaleda H. Al-Saidi \\ Department of Chemistry, College of Science, Al-Nahrain University, Baghdad, Iraq
}

\begin{tabular}{|c|c|}
\hline Articles Information & Abstract \\
\hline Received: & \multirow{12}{*}{$\begin{array}{l}\text { Normal spectra for sulfamethoxazole solutions were developed and used for the } \\
\text { determination of sulfamethoxazole (SMX) antibiotic by using zero-crossing } \\
\text { technique and simultaneously determining (SMX) at wavelength } 259.00 \mathrm{~nm} \text {. The } \\
\text { correlation coefficient of the calibration curve for the normal spectrum was } \\
0.9990 \text {. Linearity was maintained by using concentrations }\left(0.990 \times 10^{-4} \mathrm{M} \text {, }\right. \\
0.996 \times 10^{-4} \mathrm{M} \text {, 0.999 } \times 10^{-4} \mathrm{M}, 1.004 \times 10^{-4} \mathrm{M}, 1.005 \times 10^{-4} \mathrm{M} \text { ) and the percentage } \\
\text { recovery of sulfamethoxazole samples were }(99.00 \%, 99.60 \%, 99.90 \%, 100.40 \% \\
\text { and } 100.50 \% \text { ). A statistical analysis confirmed, a precision with accuracy for } \\
\text { simultaneous fixing of (SMX). In addition, a British pharmacopoeia method was } \\
\text { compared with the method used in this paper using F test. }\end{array}$} \\
\hline 21.06 .2020 & \\
\hline Accepted: & \\
\hline 06.10 .2020 & \\
\hline Published: & \\
\hline 01.12 .2020 & \\
\hline Keywords: & \\
\hline UV-spectrophotometry & \\
\hline Normal spectrum & \\
\hline Sulfamethoxazole & \\
\hline Analytical methods & \\
\hline Direct method & \\
\hline
\end{tabular}

DOI: 10.22401/ANJS.23.4.01

*Corresponding author: sarraaabrahem@ gmail.com

\section{Introduction}

Sulfamethoxazole (SMZ) $\mathrm{C}_{10} \mathrm{H}_{11} \mathrm{~N}_{3} \mathrm{O}_{3} \mathrm{~S}$, as shown in the Figure 1, is a crystalline and white powder, with molecular weight $253.279 \mathrm{~g} / \mathrm{mole}$, freely soluble in acetone, practically insoluble in the water, in ethanol sparingly soluble. As well as dissolves it in acids and in sodium hydroxide after diluted. Meanwhile also considered as a sulfonamide bacteriostatic antibiotic. In a synergistic combination, sulfamethoxazole is often used alongside trimethoprim in a ratio $(5: 1)$, in the co-trimoxazole [1]. Researchers have developed various analytical methods to determine sulfamethoxazole in biological samples and formulations, such as ion selective electrodes [2-4], chromatographic [5,6], and HPLC (High Performance Liquid Chromatography) [7-9] methods. UV spectrophotometer can be used to investigate the interaction of matter with light radiation in visible (400800) range and the ultra-violet (200-400) [10,11]. UV radiation has enough energy to excite valence electrons in molecules or many atoms from their terrestrial state to higher energy levels. In such a process, excited electrons move from bond to anti-correlation orbits [12]. The typical applications of UV absorption spectroscopy comprise the determination of poly nuclear aromatic compounds such as vitamins, painting materials, and drugs [13]. In addition, several applications of visible spectrophotometric methods have been developed for the purpose of analysis of various colored compounds as well as, different colored metal complexes [13]. In this research, the determination of
Sulfamethoxazole was obtained in pharmaceutical samples using direct method for calibration curve of normal spectrum of UV-spectrophotometry at $\lambda(259.00 \mathrm{~nm})$ for five samples of SMZ standard solution.

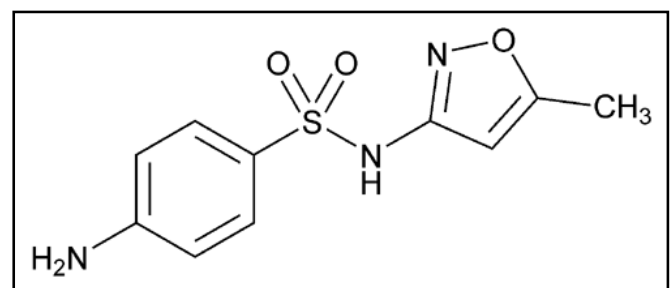

Figure 1. Structure formula of sulfamethoxazole.

\section{Experimental Part}

\section{Instruments and equipment}

The Shimadzu UV-1650 PC, UV-Visible, double-beam spectrophotometer (Japan) was interfaced via a data system of the Shimadzu UV probe software version 1.10, $1.00 \mathrm{~cm}$ quartz cells, (W. Germany) with Sartorius Handy of four-digit analytical Balance.

\section{Reagents and solutions}

The standard sulfamethoxazole, was a gift from the public company for Pharmaceutical and medical devices (Samara IRAQ-SDI). Trimol tablets were purchased each tablet (containing $400 \mathrm{mg}$ sulfamethoxazole) from Bilim Pharmaceuticals (Made in UAE). The other reagents and solvents get from $\mathrm{BDH}$. 


\section{Al-Nahrain Journal of Science}

ANJS, Vol.23 (4), December, 2020, pp. 1-4

\section{Procedure}

\section{Preparation working standard solutions}

1. The $20 \%$ acetone solution was prepared by diluting $200 \mathrm{ml}$ of acetone and supplementing it in a solution of $1000 \mathrm{ml}$ with the distilled water.

2. Series of different solutions $\left(0.990 \times 10^{-4} \mathrm{M}, 0.996 \times\right.$ $\left.10^{-4} \mathrm{M}, 0.999 \times 10^{-4} \mathrm{M}, 1.004 \times 10^{-4} \mathrm{M}, 1.005 \times 10^{-4} \mathrm{M}\right)$ were prepared from $\left(1 \times 10^{-3}\right) \mathrm{M}$ sulfamethoxazole solution above.

\section{Results and Discussion}

Figure 2 shows the normal spectra for sulfamethoxazole solutions $\quad\left(0.990 \times 10^{-4}, \quad 0.996 \times 10^{-4}, \quad 0.999 \times 10^{-} 4\right.$, $\left.1.004 \times 10^{-4}, 1.005 \times 10^{-4}\right) \mathrm{M}$, the absorption wavelength at $259.00 \mathrm{~mm}$.

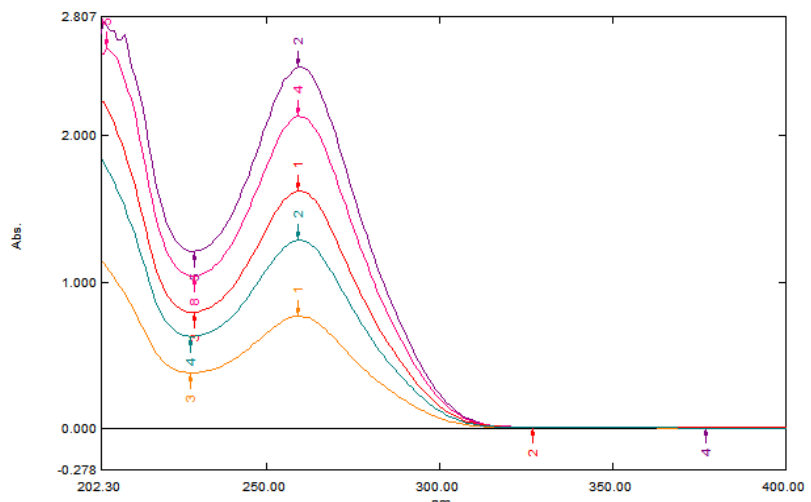

Figure 2. The normal spectra for SMZ solutions.

The calibration curve was constructed for a wavelength (259.00) nm as shown in Figure 3.

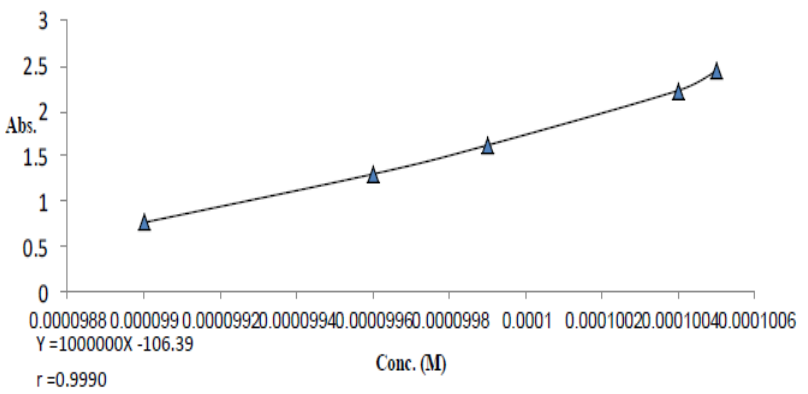

Figure 3. Calibration curve of normal spectrum for SMZ at $\lambda 259.00 \mathrm{~nm}$.

Figure 3 shows the calibration curve of normal spectrum at the $\lambda 259.00 \mathrm{~nm}$, from a linear equation of the calibration curve $(\mathrm{Y}=1000000 \mathrm{x}-106.39)$ the concentration of sulfamethoxazole can be calculated. Table 1. Show the results of sulfamethoxazole.
Table 1. Calculation for five samples of 10-4of SMZ standard solution by using direct method for calibration curve of normal spectrum of UV-spectrophotometry at $\lambda$ $(259.00 \mathrm{~nm})$.

\begin{tabular}{|c|c|c|c|c|c|c|}
\hline Abs & $\begin{array}{c}\text { Conc. } \\
(M)\end{array}$ & $\delta_{n-1} *$ & $\underset{(t s / \sqrt{N})}{X \pm}$ & $\operatorname{Re} \%$ & Er\% & RSD $\%$ \\
\hline $\begin{array}{l}\stackrel{t}{0} \\
\stackrel{0}{0}\end{array}$ & $\begin{array}{l}+ \\
0 \\
x \\
8 \\
o \\
o \\
0\end{array}$ & \multirow{5}{*}{ 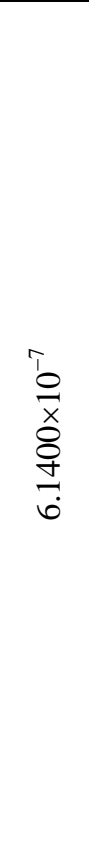 } & \multirow{5}{*}{ 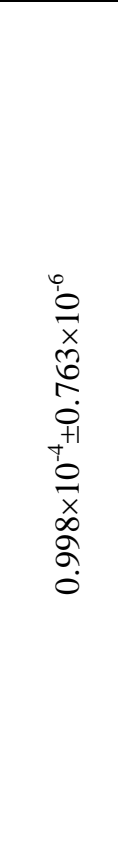 } & $-1 \%$ & $\begin{array}{l}80 \\
8 \\
8 \\
\dot{\alpha}\end{array}$ & \multirow{5}{*}{$\begin{array}{l}00 \\
i \\
i n \\
0 \\
0 \\
0\end{array}$} \\
\hline 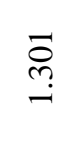 & 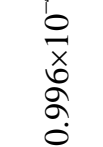 & & & $-0.4 \%$ & $\begin{array}{l}80 \\
\text { : } \\
8 \\
2\end{array}$ & \\
\hline 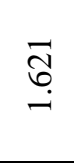 & 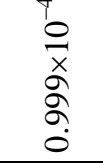 & & & $-0.1 \%$ & $\begin{array}{l}\text { o̊ } \\
\circ \\
\text { aे }\end{array}$ & \\
\hline $\begin{array}{l}\stackrel{\infty}{\simeq} \\
\stackrel{i}{i}\end{array}$ & $\begin{array}{l}1 \\
0 \\
x \\
\text { o } \\
8 \\
\end{array}$ & & & $0.4 \%$ & $\begin{array}{l}\stackrel{8}{0} \\
\text { +े. } \\
8 \\
8\end{array}$ & \\
\hline $\begin{array}{l}\stackrel{0}{0} \\
\text { ì } \\
\text { i }\end{array}$ & 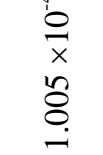 & & & $0.5 \%$ & $\begin{array}{l}\stackrel{0}{0} \\
0 \\
0 \\
0 \\
0\end{array}$ & \\
\hline
\end{tabular}

RSD: Relative standard deviation, $\mathrm{Re} \%$ : The percentage recovery, Er: Relative error.

The calculated linear equation for normal spectrum, correlation coefficient and concentration are listed in Table 2.

Table 2. Calculation linear equations, correlation coefficient and the range of concentrations for the normal spectrum.

\begin{tabular}{|c|c|}
\hline Method & Normal spectrum \\
\hline $\mathrm{nm}(\lambda)$ & 259.00 \\
\hline Concentration $(\mathrm{M})$ & $1.06 \times 10^{-4}$ \\
\hline Linear equation & $\mathrm{y}=1000000 \mathrm{x}-106.39$ \\
\hline (r) Correlation Coefficient & 0.9990 \\
\hline
\end{tabular}




\section{Al-Nahrain Journal of Science}

ANJS, Vol.23 (4), December, 2020, pp. 1-4

\section{Comparison between ISE and normal spectrum methods}

Table 3. The value of the F test between the ISE and normal spectra.

\begin{tabular}{|c|c|c|c|c|}
\hline $\begin{array}{c}\text { CU(M) } \\
\text { from } \\
\text { direct } \\
\text { Method of } \\
\text { ISE }\end{array}$ & $\delta_{n-1} *$ & $\begin{array}{c}\text { CU(M) from } \\
\text { direct } \\
\text { method of } \\
\text { normal } \\
\text { spectrum }\end{array}$ & $\delta_{n-1}^{*}$ & $\begin{array}{c}\text { The }(\mathrm{F}) \\
\text { magnitude }\end{array}$ \\
\hline $0.993 \times 10^{-4}$ & \multirow{5}{*}{$\begin{array}{l}T \\
\stackrel{0}{x} \\
x \\
\infty \\
o \\
\dot{\gamma} \\
\dot{+}\end{array}$} & $0.990 \times 10^{-4}$ & \multirow{5}{*}{$\begin{array}{l}\hat{0} \\
x \\
0 \\
+ \\
0 \\
0\end{array}$} & \multirow{5}{*}{2.244} \\
\hline $0.998 \times 10^{-4}$ & & $0.996 \times 10^{-4}$ & & \\
\hline $0.992 \times 10^{-4}$ & & $0.999 \times 10^{-4}$ & & \\
\hline $1.002 \times 10^{-4}$ & & $1.004 \times 10^{-4}$ & & \\
\hline $0.998 \times 10^{-4}$ & & $1.005 \times 10^{-4}$ & & \\
\hline
\end{tabular}

$\delta_{\mathrm{n}-1} *$ : standard deviation; $\mathrm{n}=5, \mathrm{~F}=\mathrm{S} 12 / \mathrm{S} 22$, where $\mathrm{S} 1>$ $\mathrm{S} 2$, F Table $=6.39$.

Table 3 shows the comparison between the (normal spectrum) and the (direct method) of ISE using the F-test using a 95\% confidence level and this table show standard deviation $\left(\delta_{n-1}\right)$ for five measurements where $\mathrm{F}=\mathrm{S} 12 / \mathrm{S} 22$, where $\mathrm{S} 1>\mathrm{S} 2$ and $\mathrm{F}$ Table equal 6.39 and from the calculations it found F Calculate is less than F Table, and thus, there is no difference in precision between the two methods. Sulfamethoxazole potentiometric determination in pharmaceutical preparations and the data obtained for pharmaceutical samples were listed in Table 4 [14].

Table 4. Analyses of SMZ in pharmaceutical samples.

\begin{tabular}{|c|c|c|c|c|}
\hline Parameter & Direct method ${ }^{*}$ & Standard addition method* & Multi SAM* & Titration method*** \\
\hline Conc. (Molar) & 0.0001 & 0.0001 & 0.0001 & 0.0001 \\
\hline Found (Molar) & $0.998-10^{-4}$ & $0.998 \times 10^{-4}$ & $1.002 \times 10^{-4}$ & $0.999 \times 10^{-4}$ \\
\hline RSD $^{*} \%$ & 0.647 & 0.885 & - & 0.919 \\
\hline Re \% & 99.820 & 100.980 & 100.200 & 99.95 \\
\hline Er \% & -0.180 & -0.360 & 0.200 & -0.05 \\
\hline S & $6.457 \times 10^{-7}$ & $8.820 \times 10^{-7}$ & - & $9.192 \times 10^{-7}$ \\
\hline$X \pm(t s / \sqrt{ })$ & $0.998 \times 10^{-4}+0.779 \times 10^{-6}$ & $0.998 \times 10^{-4}+0.779 \times 10^{-6}$ & - & $0.999 \times 10^{-4}+0.825 \times 10^{-5}$ \\
\hline
\end{tabular}

RSD: Relative standard deviation, RSD***\% for $\mathrm{n}=2, \mathrm{t}=12.7, \mathrm{RSD} * * \%$ for $\mathrm{n}=3, \mathrm{t}=4.3, \mathrm{RSD} * \%$ for $\mathrm{n}=5, \mathrm{t}=2.7, \mathrm{Re} \%$ : The percentage recovery, $\mathrm{E}_{\mathrm{r}}$ : Relative error.

\section{Conclusions}

Analytical methods proved to be simple and fast. The results obtained from these methods are in good agreement, in terms of accuracy, with a direct method of selective ion electrode for analysis of the study using the F test at a $95 \%$ confidence interval compared with the normal spectrum.

\section{Acknowledgment}

We would like to thank all participants in this research in addition to Al-Nahrain University for providing an environment for research.

\section{References}

[1] British Pharmacopoeia; "Medicinal and pharmaceutical substances", Published by the Stationery Office on behalf of the Medicines and Healthcare products Regulatory Agency (MHRA) 1(2), 1406-1407, 2014.

[2] Al-Saidi, K. H.; and Munshid H. Q.; "New polymeric membrane electrode for clarithromycin determination"; Al-Nahrain J. Sci.16 (2), 30-36, 2013.

[3] Abrahem, S. A.; Abdul Kader A. S.; Ibrahim, S.A.; "Determination of clarithromycin and its applications in pharmaceutical samples using new selective electrodes"; J. Global Pharma Tech. 11(9), 673-679, 2019.

[4] Ismaeel, Y. Q.; Al-Phalahy, B. A.; "A new cyproheptadine PVC ion selective electrode and their applications in pharmaceutical preparations and human fluids"; Al-Nahrain J. Sci.23(2), 26-32, 2020.

[5] Jiang, Y.; Wang, J.; Li, H.; Wang, Y.; Gu, J.; "Determination of sulfamethoxazole in human plasma by liquid chromatography-electrospray ionization tandem mass spectrometry"; J. Pharm Biomed Anal. 43, 1460-1464, 2007.

[6] Punnamchand, L.; Poornima, D. H.; "A simple, rapid, and sensitive HPTLC method for the estimation of sulfamethoxazole: Application to single dose clinical study"; J. Planar Chrom. 24, 534-538, 2012.

[7] Wei, L.; Huijuan, J.; Kang, Z.; "Determination of sulfamethoxazole in rat plasma by HPLC-UV method with pre-column derivatization"; Talanta. 71, 385-390, 2007.

[8] Wibawa, J. I. D.; Shaw, P. N.; Barrett, D. A.; "Quantification of sulfamethoxazole and decladinose metabolites in rat plasma, gastric juice and gastric 


\section{Al-Nahrain Journal of Science}

ANJS, Vol.23 (4), December, 2020, pp. 1-4

tissue using high-performance liquid chromatography

with electrochemical detection"; J. Chromatogr. B 783, 359-366, 2006.

[9] Pappa-Louisi, A.; Papageorgiou, A.; Zitrou, A.; Sotiropoulos, S.; Georgarakis, E.; Zougrou, F.; "Study on the electrochemical detection of the macrolide antibiotics sulfamethoxazole and trimethoprim in reversed-phase high-performance liquid chromatography"; J. Chromatogr. Biomed. Appl. 755, 57-64, 2001.

[10] Adeeyinwo, C.; Okorie, N.; Idowu, G.; "Basic calibration of UV/visible spectrophotometer"; Int. J. of Sci. and Tec. 2(3), 247-251, 2013.

[11] Saleem, F.; Khan, N.; Ali, I.; "Synthesis of hydroxamic ligands with transition metal complexes, their biological activities and characterization through spectroscopic techniques"; Al-Nahrain J. Sci. 23(2), 1-7, 2020.

[12] Ganjali, M. R.; Vesimohammadi, B.; Riahi, S.; Norouzi, P.; "Promethazine potentiometric membrane sensor for promethazine hydrochloride pharmaceutical analysis; computational study"; Int. J. Electrochem. Sci. 4, 740-754, 2009.

[13] Malih, I. K.; "A study on new metoclopramide hydrochloride membrane electrodes"; M.Sc. thesis, Ibn Al-Haitham univ., 2009.

[14] Abrahem, S.A.; Al-Saidi, K. H; "New polymeric ion selective electrode for determination of sulfamethoxizole in pure and pharmaceutical samples"; Al-Nahrain J. Sci. 18(2), 25-32, 2015. 